\title{
Migrants and Refugees in Europe: Challenges, Experiences and Contributions
}

\author{
Tobias Schilling $^{a}$ Stephan Rauscher ${ }^{a}$ Christian Menzel ${ }^{a} \quad$ Simon Reichenauer $^{a}$ \\ Martina Müller-Schilling ${ }^{b}$ Stephan Schmid ${ }^{b}$ Michael Selgrad $^{b}$ \\ a Interdisciplinary Emergency Department, Katharinenhospital Stuttgart, Stuttgart, Germany; \\ ${ }^{\mathrm{b}}$ Department of Internal Medicine I, University Hospital Regensburg, Regensburg, Germany
}

Keywords

European refugee crisis - Displaced people - Refugees . Migrants · Migration · Health care $\cdot$ Health problems

\section{Summary}

Due to the current geopolitical situation more refugees from crisis countries were and will be treated in Europe. In 2015 the number of displaced people reached an unprecedented level, with more than one million crossing into Europe. The migration itself can impair both mental and physical health. Therefore, the provision of medical care for refugees and migrants is a novel and major challenge for the health care systems in Europe. In this article we describe our experiences and contribution in providing medical care for refugees who have newly arrived in Stuttgart, Baden-Wuerttemberg, Germany. Furthermore, we report our experiences from a tertiary referral University center in Regensburg, Bavaria, Germany. We focus on challenges in both the outpatient and the inpatient setting, with a special focus on intensive care patients. In addition, we provide an overview about the spectrum of diseases in this specific patient cohort.

(C) 2017 S. Karger GmbH, Freiburg

Tobias Schilling and Stephan Rauscher share first authorship. Stephan Schmid and Michael Selgrad share last authorship.

\section{Introduction}

Due to the geopolitical situation the number of refugees and migrants in Europe has increased in the past years. On a global scale, the number of migrants worldwide has reached 244 million in 2015 , which represents $3 \%$ of the world population [1]. The European Union (EU) comprises 28 member states, and in 20143.8 million people migrated to the $\mathrm{EU}$, with most of them, i.e. 1.9 million refugees, being from non-member countries [2]. In 2015 over 65 million people migrated, with more than half of them originating from war-torn countries such as Syria, Afghanistan, and Somalia. Especially, the countries in the southeast of Europe were confronted with waves of refugees; e.g., nearly one million migrants crossed the Greek border in 2015 [3].

Migration itself does not count as a risk factor for health, but the circumstances of migration are often associated with physical, mental and social health disorders. Furthermore, refugees and migrants come from very different regions to Europe; therefore, the range of expectable diseases and health problems varies considerably.

It is well known that the mortality and morbidity pattern of foreign-born individuals living in the EU varies widely among different population groups compared with the native population $[4,5]$. The country of origin and the local epidemiology are important factors when considering diseases in newly arrived migrants and refugees. Although the likelihood is low that certain infectious diseases will occur among migrants, they should still be considered in order to make sure that infectious diseases are diagnosed timely to control the risk of disease spread [6-9].

There is a considerable burden of communicable and non-communicable disease among newly arrived refugees and migrants.

In this review, we focus on specific aspects of medical care for newly arrived migrants and refugees in Europe. We report our experience in providing health care at reception of large cohorts of

\section{KARGER}

() 2017 S. Karger GmbH, Freiburg

Fax +497614520714
PD Dr. med. Michael Selgrad

Klinik und Poliklinik für Innere Medizin I

Universitätsklinikum Regensburg

Franz-Josef-Strauß-Allee 11, 93053 Regensburg, Germany

michael.selgrad@ukr.de 
refugees in 2015 and in building up reception centers in a multidisciplinary team, as well as our experience in inpatient care.

\section{Specific Challenges during Early Settlement in a Reception Center in Stuttgart, Germany}

The arrival of large numbers of refugees within a short time period is a challenge for the medical system in its entirety. Health care should be provided by a multidisciplinary team in coordination with the local health care systems and other organizations.

We describe our experiences from a large community hospital in Stuttgart, Germany, in the summer and autumn of 2015. On a Sunday in August 2015, the staff of the emergency department was notified that a reception center had been established that day in a local concert and sports hall housing around 500 refugees, mostly from Syria and Afghanistan. The refugees had travelled via the Balkan route and were transferred to Stuttgart from the Austrian border in buses. Immediately after the arrival in the reception center, the first patients were transported to our emergency department, and within the first $24 \mathrm{~h}$ ambulance services and general practitioners were constantly called to the newly established reception center. We realized soon that health care for refugees and asylum seekers should be based on a holistic approach, including early health assessment and management of communicable and non-communicable diseases, such as chronic diseases as well as mental and social problems, including the provision of ongoing care. The following obstacles for the establishment of an inclusive and culturally sensitive health system were encountered in our emergency department:

- Communication with the patients was difficult or impossible as most of them spoke neither German nor English. Translators had to be organized, and waiting times for translators amounted sometimes to several hours.

- Furthermore, to ensure efficient communication, cultural mediators and interpreters had to be identified and integrated in the medical care team.

- Triage had to be organized to prioritize patients with acute illness - both physical and mental -, in particular for sensitive patient groups, i.e. children, unaccompanied minors, pregnant women, and the elderly.

- The funding of the medical care for refugees was backed by local authorities; however, the requirements for documentation and billing were completely different from other patients and therefore caused an extra workload for the emergency department.

- Prescribing medications as usual was impossible as most refugees could not obtain the medication with a prescription from local pharmacies due to a lack of health insurance and money.

- After having received treatment, patients that had arrived by ambulance did not know how to return to the refugee center as they had neither money nor knowledge of the place to use public transport systems.

We realized soon that treating these patients in the emergency department was very inefficient. Therefore, we organized consultation hours in the refugee center with physicians from our hospital and medical assistance from the volunteers of the Order of Saint John and the German Red Cross. All of the physicians were volunteers - not only from our emergency department but also from other departments of our hospital. Thus, we established a multidisciplinary team, recruiting interpreters, cultural mediators, and social workers in order to coordinate care provision and follow-up among various providers in the refugee center. This resulted in an almost immediate improvement of the medical situation and marked a starting point of an inclusive and culturally sensitive health care immediately after arrival in the refugee center.

As soon as these medical consultation services were established in the refugee camp, the number of calls of ambulance services and the number of patients that presented themselves to the emergency department dropped to almost zero while we saw up to 50 patients in the refugee camp every day (fig. 1).

Most of the patients could be treated sufficiently in the camp. We were confronted with airway infections, small wounds, pain caused by old battlefield injuries as well as scabies and lice. A small proportion of the patients was sent to hospital outpatient clinics or to practitioners (mostly dentists and gynecologists), if the treatment could not be organized directly in the center.

Apart from some cases of suspected tuberculosis (TB), we saw almost no serious medical conditions or major traumatic injuries that required in-hospital emergency treatment. This was probably due to the fact that refugees who started the long journey to Europe were generally in a good medical condition and those who acquired serious diseases or trauma during the journey had already been identified and had received medical treatment in Austria or in Bavaria close to the Austrian border.

Furthermore, communication with the patients in the refugee center was much easier because other refugees - in addition to the interpreters in our team - volunteered to translate from the mother tongue of the patient to English.

In addition, we organized the supply of medications from a pharmacy close by which delivered the prescribed medications already 'individualized' and labelled with the name of the patient and with a finely tuned medication regimen included.

After a few days of rest in the center most of the refugees recovered and the number of refugees needing medical care decreased. Especially diseases that are related to poor hygienic conditions during the journey, such as scabies or lice, almost disappeared after 2-3 weeks.

During the autumn of 2015, several other refugee centers were established in Stuttgart to accommodate up to 2,500 people. Due to our good experiences with immediate-onset consultation hours in the first center, we established consultation hours in all other camps upon arrival of the refugees and migrants. As a result, we were able to provide instant care and to efficiently coordinate care provision and follow-up among various other providers and settings. As the need for medical care was only very high at the beginning, i.e. directly after the arrival of the refugees in Germany, and decreased during the following weeks and as the number of refugees in the camps declined, it was possible to integrate the refugees into our public health system. Thus, the consultation hours in the 
Fig. 1. Reduction of the ambulance emergency services and the number of patients that presented themselves to the emergency room (ER) at the hospital after installation of a daily physician consultation service at the refugee camp.

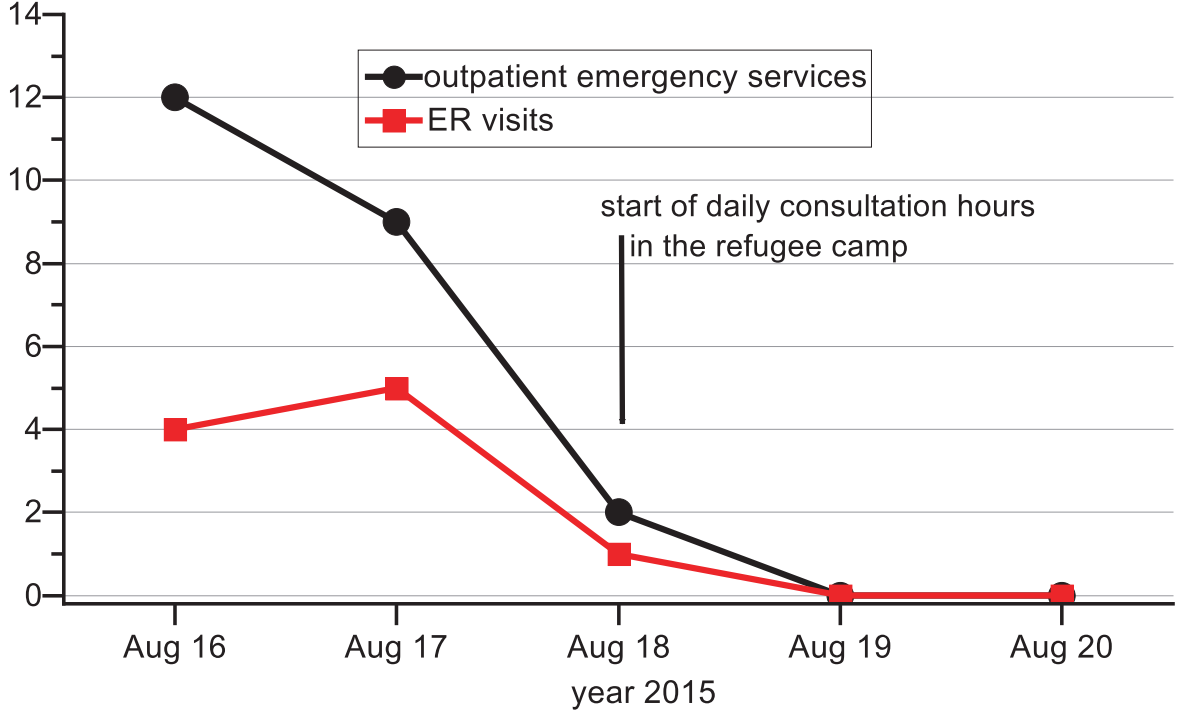

centers could be terminated after 6 months and had not only provided immediate and efficient care for the arriving migrants and refugees but also generated a holistic approach that resulted in the integration of the refugees in our public health system.

In conclusion, intersectoral collaboration is important to meet the different needs of this special patient population, multidisciplinary teams have to be formed, and newly arrived migrants should receive an immediate health reception or welcome in the refugee center. All following medical actions and interventions should be coordinated from the local refugee center, and all services and providers that were involved in the treatment of refugees need to be informed about special characteristics of refugee care: communication, mental and physical care, transport logistics, supply of medications, and requirements for documentation and billing.

\section{Specific Communicable and Non-Communicable Diseases and Challenges}

Different aspects need to be considered when analyzing the migration process regarding infectious diseases, e.g. the country of origin, the period from the move to first arrival, settlement in refugee camps/other reception sites, and resettlement.

\section{Health Problems during Travel and First Arrival}

The duration of the migration status can have a significant impact on the health of migrants and refugees. The most common health problems may be related to problems in their home countries and the journey, representing a variety of diseases including accidental injuries, gynecological and obstetric complications, dermatological diseases, cardiovascular events, gastrointestinal and respiratory problems, and mental illness $[10,11]$. Available evidence underlines that infectious diseases are not a health priority at first arrival [12-14]. A very recent work from Germany assessed the health status of 214 asylum seekers, and the main health prob- lem was psychological illness while the prevalence of infectious and chronic diseases was low [15]. However, vulnerable groups (children and elderly), considering that they spent long periods on their journey, are prone to respiratory and gastrointestinal infections and dermatological diseases (scabies) due to poor hygienic as well as living conditions $[12,16]$. A further important challenge is due to gender-specific problems, such as maternal, reproductive issues and access to contraception. Furthermore, female refugees are at high risk of sexual abuse and pregnancy due to poor access to contraception [17]. Nutritional problems, exposure to violence, and possible drug and alcohol abuse may increase the risk for noncommunicable diseases [18]. Therefore, access to preventive health care (screening) as well as prenatal and obstetric care is mandatory and crucial for refugees and migrants after first arrival.

\section{Health Problems in Refugee Camps and Other Reception Sites}

'The relation between migration and infectious disease is complicated', is stated in an editorial in The Lancet Infectious Diseases from 2016, and 'there is no systematic association between migration and importation of infectious diseases' [19]. The World Health Organization (WHO) does not recommend compulsory mass screening of refugees. However, the WHO does recommend health eases. Screening programs should be rationalized and evidencebased and address newly arrived refugees from countries with a large disease burden. Particularly, assessment of immunization status might be important to reduce the risk of outbreaks. In an attempt to establish more evidence for health assessment and health care, a new initiative between Cochrane, Wiley, Kevin Pottie, Leo Ho, and Evidence Aid identified some of the most relevant medical conditions as perceived by experts who have been involved either in guideline development or 'on the frontline', thus directly addressing the needs of refugees and asylum seekers [20]. In the first instance, the collaboration decided on the following priority conditions to be addressed: checks for both infectious diseases and non-communicable dis- 
- Common mental health disorders (including posttraumatic stress disorder (PTSD) and depression): PTSD is highly prevalent in children and adolescents who have experienced trauma and is associated with high personal and health costs. In particular, newly arrived people present with anxiety disorders, depression, alcoholism, and drug abuse as a consequence of traumatic experiences related to war, dislocation, and physical and sexual abuse.

- Vaccine-preventable diseases: Well-documented outbreaks of vaccine-preventable diseases among migrants and refugees such as measles or varicella have been reported [21]. Thus, access to vaccination is of prime importance. According to the WHO, vaccinations may include: measles, mumps, and rubella (for children below 15 years); poliomyelitis for children and adults from countries exporting poliovirus; meningococcal disease; tetanus, pertussis, and diphtheria; and influenza depending on the season [22].

- Skin conditions (including impetigo, scabies, and cellulitis): Skin infections are common among those forcibly displaced, as they have to endure inadequate shelter and sanitation while travelling or in crowded reception centers. Vector-borne diseases such as lice-, flea- and mite-transmitted infections are common under conditions with poor hygienic standards.

- TB: Refugees and asylum seekers are at higher risk of getting infected or developing TB, depending on the TB incidence in their country of origin and poor access to health services during migration. Early diagnosis and effective treatment should be provided by the countries receiving these people.

- Sexual and physical violence: Women are at high risk for sexual and physical violence as well as gender-based violence.

One of the most important factors considering infectious diseases are the country of origin and the local epidemiology. According to the WHO, screening of migrants for diseases is not obligatory. However, screening for defined diseases such as latent TB, viral hepatitis, and intestinal parasites in high-risk groups was shown to be cost-effective [23, 24].

The most common disease screened in EU countries is TB [25]. Others include human immunodeficiency virus (HIV), hepatitis B, hepatitis $\mathrm{C}$, and, to a lesser extent, sexually transmitted diseases and vaccine-preventable diseases.

Pulmonary TB represents the disease with the greatest concerns. Syria, Iraq, Afghanistan, Eritrea, and Somalia are the most common countries of migrants and refugees coming to the EU, with an incidence of TB varying from 17 new cases per 100,000 in Syria up to 499 per 100,000 in Eritrea [26]. The average TB rate in the EU is 39 per 100,000 inhabitants [27]. In this context, a recent systematic review of 51 studies on crisis-affected populations described a 20fold increase of TB cases among them [28]. Therefore, a rapid and efficient clinical evaluation of refugees and migrants after arrival is mandatory. Considering the key symptoms of TB (fever, cough of at least 2 weeks' duration, weight loss, night sweats), the majority of individuals at risk can be identified and should be referred to a hospital for assessment and early treatment initiation. In a population-based cross-sectional study, Aldridge et al. [29] screened
476,455 visa applicants in the UK for TB, and migrants reporting contact with an individual with TB had the highest risk of TB at pre-entry screening. As a consequence, the authors call for a comprehensive and collaborative approach between countries with preentry screening programs as well as health services in the countries of origin and migration to tackle the disease [29].

\section{Health Problems after Resettlement}

After resettlement, chronic infections come to the fore that have already been acquired in the country of origin. The most important infections according to current evidence are infections with HIV, chronic viral hepatitis, Helicobacter pylori, and other chronic parasitic infections. For these conditions, knowledge of the prevalence of the infection in the country of origin is mandatory.

The prevalence of HIV in the five most common countries of origin of refugees and migrants is relatively low; however, $35 \%$ of new HIV cases in the EU are attributable to migrants [27, 30]. Interestingly, current evidence shows that HIV is often acquired in the post-migration phase in the EU [31]. This underlines the importance of education and prevention.

Chronic hepatitis B shows the highest seroprevalence rate among migrants and refugees. This especially accounts for people from East Asia and sub-Saharan Africa (HBsAg-positive >10\%) [32]. For hepatitis $\mathrm{C}$, a recent systematic review and meta-analysis including data from 38,635 migrants revealed a seroprevalence of $1.9 \%$ among migrants from all world regions. Older age and region of origin, particularly sub-Saharan Africa, Asia, and Eastern Europe, were the strongest predictors of HCV seroprevalence reaching more than $2 \%[33]$.

Refugees and immigrants from developing countries settling in industrialized countries have a high prevalence of $H$. pylori and therefore an increased risk for the development of $H$. pylori-associated complications such as peptic ulcer disease and gastric cancer [34]. A recent work demonstrated that screening for $H$. pylori in migrants and refugees is cost-effective and has the potential to reduce the risk of gastric cancer and peptic ulcer disease [35].

\section{Experiences from a Medical Intensive Care Unit at a University Medical Center of Tertiary Care in Eastern Bavaria}

Comprehensive information on migrant and refugee health in the intensive care setting is rare in the current literature. One study from Turkey reported that refugees presented to intensive care units (ICUs) with common infections (pneumonia and urinary tract infections), but had high mortality rates [36].

As stated above, most refugees with very serious diseases were identified in reception centers near the border between Bavaria and Austria. These patients were admitted to local hospitals.

Defined patients in life-threatening conditions were transferred to our medical ICU at the University Hospital Regensburg, Germany.

Altogether, 5 refugees in very severe medical conditions were treated at our ICU from the summer of 2015 until the spring of 
Table 1. Definitions of the terms asylum seeker, migrant, and refugee

\begin{tabular}{ll}
\hline Asylum seeker & $\begin{array}{l}\text { An individual who is seeking international protection } \\
\text { and sanctuary in a country other than the one of his/her } \\
\text { usual settlement. Not every asylum seeker will ulti- } \\
\text { mately be recognized as a refugee, but every refugee is } \\
\text { initially an asylum seeker. }\end{array}$ \\
\hline Migrant & $\begin{array}{l}\text { There is no universally accepted definition of the term } \\
\text { 'migrant'. Migrants may remain in the home country or } \\
\text { host country, move on to another country, or move } \\
\text { back and forth between countries. }\end{array}$ \\
\hline Refugee & $\begin{array}{l}\text { A person who, owing to well-founded fear of persecu- } \\
\text { tion for reasons of race, religion, nationality, member- } \\
\text { ship of a particular social group, or political opinions, is } \\
\text { outside the country of his/her nationality and is unable } \\
\text { or, owing to such fear, is unwilling to avail himself/ } \\
\text { herself of the protection of that country. }\end{array}$ \\
\end{tabular}

2016. All patients were male and aged less than 50 years. They originated from the Middle East and/or North Africa. Many of the patients needed mechanical ventilation and/or the use of vasopressors to maintain circulation.

Notably, all of the patients suffered from previously undiagnosed chronic diseases (e.g. liver cirrhosis, lymphoma, AIDS) aggravated by common infections, which were acquired during the long and troublesome journey.

All patients presented with sepsis or septic shock mostly due to pneumonia. Although all patients were isolated as a precaution according to the local recommendations, microbiological analyses showed no multidrug-resistant bacteria.

Despite the different native languages of the patients, communication could be ensured at all times with the help of translators (mostly volunteers among our employees), who could be contacted at any time via a volunteer service in our hospital. All relatives of the patients were closely involved in the treatment by our interprofessional team of the ICU.

Taken together, refugees treated at our ICU presented with infections similar to the host population (pneumonia and urinary tract infections), which is in line with the current literature $[14,36]$.

In conclusion, migrants with non-communicable diseases may be more vulnerable as a result of the difficult conditions during their journey. On the one hand, displacement results in the interruption of continuous care that is essential for the management of chronic diseases. On the other hand, as with our patients on the intensive care ward, the diagnosis of chronic, non-communicable disease had not been established due to lack of access or decimation of health care systems in their country of origin.

Overall, $51 \%$ of refugees report chronic disease [37]. In line with communicable diseases, the country of origin accounts for specific epidemiologic profiles also for non-communicable diseases. Diabetes mortality rates are higher in migrants from North Africa, the Caribbean, and South Asia [17, 22, 38]. Migrants from West Africa have a higher incidence of cerebrovascular disease, and those originating from Afghanistan, Iraq, and North Africa suffer more often from coronary heart disease $[5,17,39]$. Migrants have a higher risk for cancers that are related to infections, such as hepatocellular carcinoma, cervical cancer, and gastric cancer $[40,41]$.

\section{Conclusion}

- Involuntary migration is a global challenge.

- The number of displaced people reached an unprecedented lev$\mathrm{el}$ at a total of 60 million people worldwide in 2015. For a better understanding, table 1 gives an overview about definitions of the terms asylum seeker, migrant, and refugee [42-44].

- In 2015, more than one million people crossed into Europe.

- The continuing migration waves create economic and social as well as health-related challenges for the host countries.

- The burden of hosting large populations of displaced people requires improved coordination and cooperation by European countries.

- A long-term solution for the refugee crisis is to undertake all efforts in order to reduce the socioeconomic and health inequalities that drive consistently increasing populations worldwide to become refugees.

- A short-term solution would be to increase preparedness for the management of the specific diseases - communicable and noncommunicable - in this patient population. All interventions should be based on evidence, global disease patterns, and medical needs during the migration process.

- Early interventions in refugee camps will not only help the refugees at an individual level but will assist their integration in their host country.

- Early intervention strategies will also protect the public health of host countries.

- Close collaboration between physicians, health care workers, and public authorities is mandatory to provide adequate medical care for refugees and migrants. The task as well as challenge for the future is the integration of refugees and migrants into the existing health care systems in Europe.

\section{Disclosure Statement}

The authors have no conflict of interest to declare. 


\section{References}

1 International Organization for Migration: IOM's Global Migration Data Analysis Centre (GMDAC). http://gmdac.iom.int/ (last access: May 8, 2017).

2 eurostat Statistics Explained: Statistiken zu Wanderungsströmen und Migrantenbevölkerung. http:// ec.europa.eu/eurostat/statistics-explained/index.php/ Migration_and_migrant_population_statistics/de (last access: May 8, 2017).

3 Department of Economic and Social Affairs, United Nations: International Migration Report 2015. Highlights. Advance Copy. New York, NY, 2016. www. un.org/en/development/desa/population/migration/ publications/migrationreport/docs/Migration Report2015_Highlights.pdf(last access: May 8, 2017).

4 Reus-Pons M, Vandenheede H, Janssen F, Kibele EU: Differences in mortality between groups of older migrants and older non-migrants in Belgium, 2001-09. Eur J Public Health 2016;26:992-1000.

5 Ikram UZ, Mackenbach JP, Harding S, et al: All-cause and cause-specific mortality of different migrant populations in Europe. Eur J Epidemiol 2016;31:655-665.

6 Pavli A, Maltezou H: Health problems of newly arrived migrants and refugees in Europe. J Travel Med 2017;24: DOI: $10.1093 / \mathrm{jtm} / \operatorname{tax} 016$

7 World Health Organization. Regional Office for Europe: Migration And Health: Key Issues. www.euro. who.int/_data/assets/pdf_file/0005/293270/MigrationHealth-Key-Issues-.pdf?ua=1 (last access: June 27, 2017).

8 eurostat Statistics Explained: Migration and Migrant Population Statistics. http://ec.europa.eu/eurostat/statistics-explained/index.php/Migration_and_migrant_ population_statistics (last access: June 15, 2017).

9 World Health Organization. Regional Office for Europe, with the support of UNHCR: Toolkit for Assessing Health System Capacity to Manage Large Influxes of Refugees, Asylum-Seekers and Migrants. www.euro who.int/_data/assets/pdf_file/0018/325611/Toolkitassessing-HS-capacity-manage-large-influxes-refugeesasylum-seekers-migrants.pdf?ua=1ぬua=1 (last access: June 15, 2017)

10 Firenze A, Restivo V, Bonanno V, et al: Health status of immigrants arrived to Italian coast (Article in Italian). Epidemiol Prev 2014;38(suppl 2):78-82.

11 Eonomopoulou A, Pavli A, Stasinopoulou P, Giannopoulos LA, Tsiodras S: Migrant screening: lessons learned from the migrant holding level at the GreekTurkish borders. J Infect Public Health 2017;10:177184.

12 Alberer M, Wendeborn M, Löscher T, Seilmaier M Spectrum of diseases occurring in refugees and asylum seekers: data from three different medical institutions in the Munich area from 2014 and 2015 (Article in German). Dtsch Med Wochenschr 2016;141:e8-15.

13 Arnold F, Katona C, Cohen J, Jones L, McCoy D: Responding to the needs of refugees. BMJ 2015;351: h6731.

14 Pfortmueller CA, Schwetlick M, Mueller T, Lehmann B, Exadaktylos AK: Adult asylum seekers from the Middle East including Syria in Central Europe: what are their health care problems? PLoS One 2016;11 e0148196.

15 Führer A, Eichner F, Stang A: Morbidity of asylum seekers in a medium-sized German city. Eur J Epidemiol 2016;31:703-706.

16 Redditt VJ, Janakiram P, Graziano D, Rashid M Health status of newly arrived refugees in Toronto, Ont: Part 1: infectious diseases. Can Fam Physician 2015;61:e303-309.
17 Keygnaert I, Vettenburg N, Temmerman M: Hidden violence is silent rape: sexual and gender-based violence in refugees, asylum seekers and undocumented migrants in Belgium and the Netherlands. Cult Health Sex 2012;14:505-520.

18 De Vito E, De Waure C, Specchia ML, Ricciardi W: Public Health Aspects of Migrant Health: A Review of the Evidence on Health Status for Undocumented Migrants in the European Region. WHO Health Evidence Network Synthesis Reports. Copenhagen, WHO Regional Office for Europe, 2015.

19 The Lancet Infectious Diseases: Migration and health. Lancet Infect Dis 2016;16:867.

20 Aburrow T, Allen C, Jansen J: Evidence aid special collection for refugee health. Cochrane Colloquium Abstracts. abstracts.cochrane.org/2016-seoul/evidence-aidspecial-collection-refugee-health (last access: June 15, 2017)

21 World Health Organization. Regional Office for Europe: Migration and Health: Key Issues 2017. www. euro.who.int/en/health-topics/health-determinants/ migration-and-health/migrant-health-in-the-europeanregion/migration-and-health-key-issues $\# 292115$ (last access: June 15, 2017)

22 Bradby H, Humphris R, Newall D, Phillimore J: Public Health Aspects of Migrant Health: A Review of the Evidence on Health Status for Refugees and Asylum Seekers in the European Region. WHO Health Evidence Network Synthesis Reports. Copenhagen, WHO Regional Office for Europe, 2015. www.epgencms.europarl.europa.eu/cmsdata/upload/3a3fooc0-9a75-4c8494ad-06e4bd2ce412/WHO-HEN-Report-A5-2-Refugees_FINAL_EN.pdf (last access: June 15, 2017).

23 Pareek M, Watson JP, Ormerod LP, et al: Screening of immigrants in the UK for imported latent tuberculosis: a multicentre cohort study and cost-effectiveness analysis. Lancet Infect Dis 2011;11:435-444.

24 Veldhuijzen IK, Toy M, Hahné SJ, et al: Screening and early treatment of migrants for chronic hepatitis B virus infection is cost-effective. Gastroenterology 2010; 138:522-530.

25 Kärki T, Napoli C, Riccardo F, et al: Screening for infectious diseases among newly arrived migrants in EU/ EEA countries - varying practices but consensus on the utility of screening. Int J Environ Res Public Health 2014;11:11004-11014.

26 World Health Organization. Regional Office for the Eastern Mediterranean: Eastern Mediterranean Region. Framework for Health Information Systems and Core Indicators for Monitoring Health Situation and Health System Performance. 2015. http://applications. emro.who.int/dsaf/EMROPUB_2015_EN_1904. $p d f ? u a=1$ (last access: May 8, 2017).

27 European Centre for Disease Prevention and Control: Infectious diseases of specific relevance to newly arrived migrants in the EU EEA. ECDC Technical Document. November 19, 2015. http://ecdc.europa.eu/en/ publications/Publications/Infectious-diseases-ofspecific-relevance-to-newly-arrived-migrants-in-EUEEA.pdf (last access: May 8, 2017).

28 Kimbrough W, Saliba V, Dahab M, Haskew C, Checchi F: The burden of tuberculosis in crisis-affected populations: a systematic review. Lancet Infect Dis 2012;12: 950-965.

29 Aldridge RW, Zenner D, White PJ, et al: Prevalence of and risk factors for active tuberculosis in migrants screened before entry to the UK: a population-based cross-sectional study. Lancet Infect Dis 2016;16:962970
30 Jablonka A, Solbach P, Nothdorft S, Hampel A, Schmidt R, Behrens G: Low seroprevalence of syphilis and HIV in refugees and asylum seekers in Germany in 2015 (Article in German). Dtsch Med Wochenschr 2016;141:e128-e132.

31 Fakoya I, Álvarez-del Arco D, Woode-Owusu M, et al: A systematic review of post-migration acquisition of HIV among migrants from countries with generalised HIV epidemics living in Europe: implications for effectively managing HIV prevention programmes and policy. BMC Public Health 2015;15:561.

32 Rossi C, Shrier I, Marshall L, et al: Seroprevalence of chronic hepatitis B virus infection and prior immunity in immigrants and refugees: a systematic review and meta-analysis. PloS One 2012;7:e44611.

33 Greenaway C, Thu Ma A, Kloda LA, et al: The seroprevalence of hepatitis $\mathrm{C}$ antibodies in immigrants and refugees from intermediate and high endemic countries: a systematic review and meta-analysis. PLoS One 2015;10:e0141715.

34 Morais S, Costa AR, Ferro A, Lunet N, Peleteiro B Contemporary migration patterns in the prevalence of Helicobacter pylori infection: a systematic review. Helicobacter 2017;22:e12372.

35 Schulz TR, McBryde ES, Leder K, Biggs B-A: Using stool antigen to screen for Helicobacter pylori in immigrants and refugees from high prevalence countries is relatively cost effective in reducing the burden of gastric cancer and peptic ulceration. PLoS ONE 2014;9: e108610.

36 Turktan M, Ak O, Erdem H, et al: Community acquired infections among refugees leading to Intensive Care Unit admissions in Turkey. Int J Infect Dis 2017; 58:111-114.

37 Yun K, Hebrank K, Graber LK, Sullivan M-C, Chen I Gupta J: High prevalence of chronic non-communicable conditions among adult refugees: implications for practice and policy. J Community Health 2012;37: $1110-1118$

38 Vandenheede H, Deboosere P, Stirbu I, et al: Migrant mortality from diabetes mellitus across Europe: the importance of socio-economic change. Eur J Epidemiol 2012;27:109-117.

39 Agyemang C, Bhopal R: Is the blood pressure of people from African origin adults in the UK higher or lower than that in European origin white people? A review of cross-sectional data. J Hum Hypertens 2003;17:523534

40 Arnold M, Razum O, Coebergh J-W: Cancer risk diversity in non-western migrants to Europe: an overview of the literature. Eur J Cancer 2010;46:2647-2659.

41 Arnold M, Aarts MJ, van der Aa M, Visser O, Coebergh JW: Investigating cervical, oesophageal and colon cancer risk and survival among migrants in The Netherlands. Eur J Public Health 2013;23:867-873.

42 United Nations High Commissioner for Refugees (UNHCR); Department of International Protection (DIP); Protection Information Section (PIS): Refugees. UNHCR Master Glossary of Terms. Rev. 1. June 2006. www.refworld.org/docid/42ce7d444.html (last access: June 16, 2017).

43 UN General Assembly: Convention Relating to the Status of Refugees. July 21, 1951. www.refworld.org/ docid/3be01b964.html (last access: June 16, 2017).

44 Gisbert JP, Gisbert JL, Marcos S, Moreno-Otero R, Pajares JM: Third-line rescue therapy with levofloxacin is more effective than rifabutin rescue regimen after two Helicobacter pylori treatment failures. Aliment Pharmacol Ther 2006;24:1469-1474. 